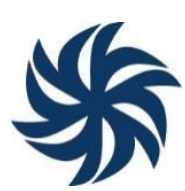

\title{
GABINETES DIGITAIS: O PAPEL DA COMUNICAÇÃO ONLINE NA ROTINA PARLAMENTAR
}

\author{
DIGITAL CABINETS: THE ROLE OF ONLINE COMMUNICATION IN \\ PARLIAMENTARY ROUTINES
}

\author{
GABINETES DIGITALES: EL PAPEL DE LA COMUNICACIÓN ONLINE EN \\ LA RUTINA PARLAMENTARIA \\ Marcio Carlomagno ${ }^{1}$, Sérgio Braga ${ }^{2}$ e Fernando Wisse ${ }^{3}$
}

\begin{abstract}
Resumo:
Este artigo investiga a utilização de ferramentas digitais pelos gabinetes parlamentares na Câmara dos Deputados. Diferentemente do que a literatura da área tradicionalmente faz, nossa pesquisa analisa o ponto de vista dos operadores do sistema. Aplicamos um survey (amostral e representativo do universo) às assessorias parlamentares trabalhando com comunicação nos gabinetes dos deputados federais. A partir de uma série de questões sobre o impacto destas ferramentas, criamos dois índices de comunicação, externa e interna. Em seguida, agregamos os dois índices e propomos uma tipologia das comunicações dos gabinetes parlamentares. Cruzamos os dados com os partidos políticos, a fim de salientar as distinções no tipo de comunicação adotada por cada um deles. Entre as contribuições desta pesquisa, reside o destaque ao uso destas ferramentas não apenas para o contato com os cidadãos, mas na organização dos gabinetes. As evidências sugerem que estas tecnologias impactam não somente as relações externas ao gabinete (sua importância como comunicação), mas a própria rotina interna de trabalho.
\end{abstract}

Palavras-chave: parlamento digital; mídias sociais; legislativo; assessorias parlamentares; internet e política.

\begin{abstract}
This article investigates the use of digital tools by parliamentary offices in the Brazilian Chamber of Deputies. Unlike the literature of the area traditionally does, our research analyzes the point of view of the system operators. We applied a survey to the parliamentary staff working with communication in MPs offices. From some questions about impact of these tools, we created two communication indexes, external and internal. Then, we propose a typology of the offices' communication. We cross the data with the political parties, in order to emphasize the distinctions in type of communication adopted by them. This research contributes to emphasizing the use of these tools not only to contact citizens, but in the offices' organization. Evidence suggests that these technologies affect not only office external relations (its importance as communication), but the internal work routine itself.
\end{abstract}

\footnotetext{
${ }^{1}$ Márcio Carlomagno é doutorando em do Programa de Pós-Graduação em Ciência Política da Universidade Federal do Paraná.

${ }^{2}$ Sérgio Braga é professor do Programa de Pós-Graduação em Ciência Política da Universidade Federal do Paraná. É doutor em desenvolvimento econômico pelo IE/Unicamp, tendo realizado estágio pós-doutoral no ICS/Institute of Communication Studies da Universidade de Leeds onde realizou pesquisas sobre os impactos das tecnologias digitais na política brasileira (2013-2014). Atualmente desenvolve pesquisas sobre internet e processos de representação política no âmbito do INCT-DD/Instituto Nacional de Ciência e Tecnologia em Democracia Digital, vinculado ao CNPq. (https://inctdd.org/)

${ }^{3}$ Fernando Wisse é doutorando do Programa de Pós-graduação em Ciência Política da Universidade Federal do Paraná.
} 
Keywords: digital parliament; social media; legislative; legislative staff; internet and politics.

Resumen

Este artículo investiga la utilización de herramientas digitales por los gabinetes parlamentarios en la Cámara de Diputados. A diferencia de lo que hace la literatura tradicionalmente, nuestra investigación analiza el punto de vista de los operadores del sistema. Aplicamos un survey (muestral y representativo del universo) a las asesorías de comunicación parlamentarias de los gabinetes de los diputados federales. A partir de una serie de cuestiones sobre el impacto de estas herramientas, creamos dos índices de comunicación, externa e interna. Em seguida, agregamos los dos índices y proponemos una tipología de las comunicaciones de los gabinetes parlamentares. Cruzamos los datos con los partidos políticos, a fin de resaltar las distinciones en el tipo de comunicación adoptada por cada uno de ellos. Entre las contribuciones de esta investigación, reside el destaque al uso de estas herramientas no sólo para el contacto con los ciudadanos, sino en la organización de los gabinetes. Las evidencias sugieren que estas tecnologías afectan no sólo a las relaciones externas al gabinete (su importancia como comunicación), sino a la propia rutina interna de trabajo.

Palabras clave: parlamento digital; redes sociales; legislativa; asesorías parlamentarias; Internet y política.

\section{INTRODUÇÃO}

Nos últimos anos, tem sido crescente o número de estudos sobre o impacto das tecnologias digitais nas relações de representação política e nas estratégias de comunicação tanto da instituição parlamentar quanto dos membros do parlamento na sua relação com o cidadão comum e com outras instituições (COLEMAN; MOSS, 2008; LESTON-BANDEIRA, 2012; LARSSON, 2014; LILLEKER et al., 2012, 2013, 2014; TENSCHER, 2014; BARROS; BERNARDES; REHBEIN, 2016). Essa quantidade crescente de estudos é, por si mesma, um indicador da importância do tema e das possibilidades da internet e das tecnologias digitais de influenciarem a natureza das relações de representação política entre elites e cidadãos, bem como o funcionamento quotidiano da governança democrática das instituições representativas. Vários analistas têm se dedicado ao tema com objetivos diferentes e métodos, universos empíricos e resultados também distintos.

Nesse contexto, muitos estudos sobre o impacto das tecnologias digitais e suas ferramentas (como website, mídias sociais e assim em diante) se centram no comportamento online dos políticos, nas mais diversas perspectivas analíticas (COLEMAN, 2005; MARQUES; AQUINO; MIOLA, 2014; NIELSEN; VACCARI, 2014), usualmente a partir de uma perspectiva "externa" de análise, ou seja, voltada para os efeitos da atividade online dos parlamentares em sua relação com o cidadão comum e outros atores da sociedade civil. Dessa perspectiva, permanecem ainda passíveis de serem objeto de análise uma série de questões mais próximas ao dia-a-dia da atividade parlamentar, dentre as quais: Como os próprios operadores do sistema, aqueles que gerenciam os mandatos parlamentares, percebem o papel destas ferramentas? Esta é nossa questão de pesquisa central da qual derivam uma série de outras a serem abordadas a 
seguir, tais como: São os gabinetes parlamentares brasileiros digitais, inseridos em uma nova lógica de representação política, ou é a utilização dessas ferramentas ainda colateral e residual no gerenciamento do mandato parlamentar? Além do uso externo, junto ao eleitorado, essas ferramentas também são utilizadas e possuem algum impacto no uso interno dos gabinetes? Como as tecnologias digitais impactam a rotina parlamentar?

Uma questão central nos estudos sobre mídias sociais tem sido como mensurar o uso e os impactos dessas tecnologias no processo de representação política. Neste artigo, procuramos inverter a pergunta diversas vezes feita pela literatura, para verificar não o impacto destas ferramentas sobre os outputs legislativos, mas - em perspectiva em boa medida rara - sobre as mudanças dentro dos gabinetes parlamentares, para a organização de sua rotina de trabalho.

Este estudo propõe dois elementos centrais, que consideramos suprir uma lacuna na pesquisa brasileira sobre mídias sociais e parlamento: a) investigar o papel das ferramentas digitais a partir da lógica interna dos atores; b) realizar esta investigação a partir das assessorias parlamentares, que são os atores que controlam e organizam o diaa-dia da rotina do mandato, mais do que o parlamentar em si.

Esse olhar para as assessorias parlamentares - que são a base do trabalho realizado no exercício de um mandato - enquanto unidade de análise, constitui uma tentativa de complementar outros estudos sobre a casa legislativa e o exercício do mandato pelos deputados empreendidos pela ciência política brasileira, via de regra muito focados na atuação do parlamentar individual, em detrimento da equipe que o cerca. Importante salientar que, no modelo adotado no legislativo federal brasileiro, os deputados dispõem, basicamente, de duas estruturas de assessoramento distintas. Uma é a Consultoria Permanente da Casa, que tem sido objeto recente de investigação (SANTOS, 2014; SANTOS; CANELLO, 2016), composta por servidores concursados, que fornecem informações e análises, quando solicitados, essencialmente sobre temas relacionados à elaboração de políticas públicas. Outra, são os assessores parlamentares políticos, que ocupam cargos em comissão, à escolha de cada deputado. Estes trabalham diretamente nos gabinetes e assessoram o dia-a-dia da rotina parlamentar. Há, além destes, as estruturas de assessorias vinculadas às lideranças partidárias. Nossa escolha da unidade de análise contempla apenas os assessores lotados diretamente nos gabinetes dos deputados, em cargos de confiança. Isto porque são estes que tendem a lidar mais diretamente com as questões políticas em sentido estrito, tópico no qual se insere nossa pesquisa sobre a comunicação política dos deputados. 
Como método, aplicamos um survey ${ }^{4}$ às assessorias parlamentares dos gabinetes dos deputados federais na Câmara dos Deputados. Obtivemos 144 respostas (28\% do universo) distribuídas em uma amostra representativa deste universo, conforme detalharemos na seção sobre o desenho de pesquisa.

Inicialmente, vamos apresentar alguns dados iniciais sobre o uso das mídias sociais pelos parlamentares brasileiros, para contextualizar o fenômeno que iremos tratar e demonstrar sua importância. Os dados se referem aos deputados federais brasileiros e foram coletados pelo GEIST/Grupo de Pesquisa em Atores, Instituições e Tecnologias Digitais, antes do início da campanha eleitoral de 2014 e se referem à $54^{\mathrm{a}}$ Legislatura, período no qual foi aplicado nosso questionário. Primeiramente, podemos verificar a utilização de diversos tipos de plataformas (websites, uma ferramenta já tradicional, e três tipos de mídias sociais) pelos parlamentares.

Gráfico 1 - Porcentagem de uso das plataformas pelos deputados federais $(n=513)$

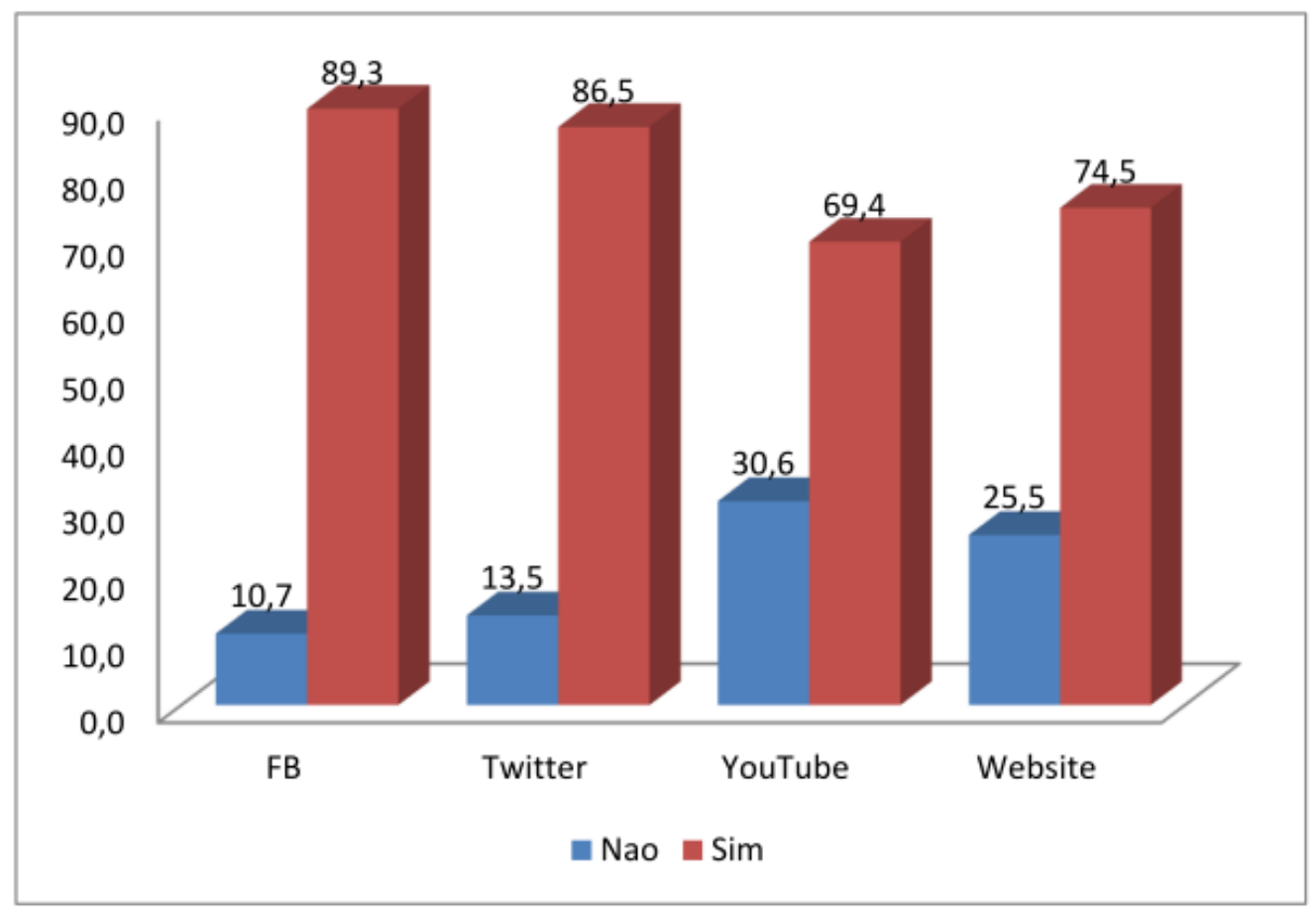

Fonte: Geist (2018). Base da dados sobre o uso das tecnologias digitais pelos parlamentares brasileiros.

\footnotetext{
${ }^{4}$ Survey é o termo técnico para pesquisa de opinião pública, que utiliza questionários fechados e é amostral. Isto é, a partir de uma amostra pode-se obter a opinião do universo de representados.
} 
Como se percebe, e como estudos já apontaram para o caso dos deputados estaduais (BRAGA; CARLOMAGNO; RODRIGUES, 2014) ou para o caso dos candidatos a governador e senador (BRAGA; CARLOMAGNO, 2018), o Facebook já é o veículo de comunicação digital de maior utilização por vários segmentos das elites políticas e parlamentares, superando (por pouco) o Twitter, que nas eleições de 2010 havia sido recurso digitais mais utilizado pelos políticos (BRAGA; CARLOMAGNO, 2018). Youtube e website parecem ser relegados a um segundo plano. Mas não basta estar presente nestas plataformas, é preciso nutri-las. Conferimos, a seguir, a frequência de atualização que os parlamentares realizam.

\section{Gráfico 2 - Porcentagem da frequência de atualização nas mídias sociais $(\mathbf{n}=\mathbf{5 1 3})$}

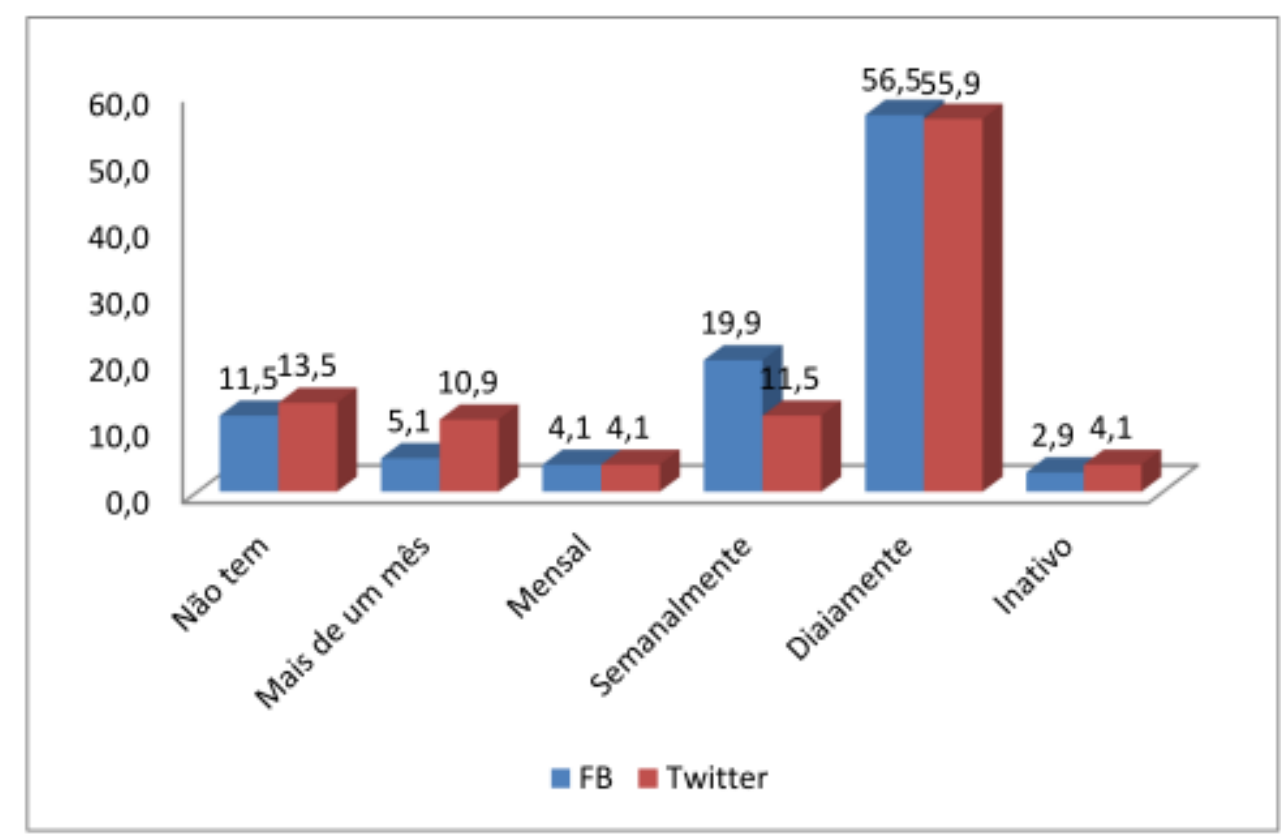

Fonte: Geist (2018).

Somando as atualizações diárias com as semanais, podemos considerar em torno de $70 \%$ a $75 \%$ dos parlamentares brasileiros como ativos nestas redes e não apenas possuindo uma plataforma digital sem utilizá-la de fato. Assim, como apontado por outros pesquisadores (MARQUES, 2013; BRAGA; ROCHA; VIEIRA, 2015), as redes digitais já se incorporaram ao quotidiano da atuação política da maioria dos representantes eleitos ao parlamento federal brasileiro. Entretanto, sabe-se que, salvo algumas exceções, não 
são diretamente os parlamentares os responsáveis pela gestão dessas mídias. Para isso, contam com um corpo de assessores encarregados de gerenciar esta assim como outras dimensões do exercício do mandato, que cada vez mais assume um perfil profissionalizado à medida que a democracia e as casas legislativas brasileiras se institucionalizam.

Dentro desse contexto, o objetivo deste artigo é identificar como os gabinetes utilizam as ferramentas de tecnologia digital, tanto para uso externo (comunicação com cidadãos) quanto para uso interno (rotina do gabinete). Assim, nossa unidade empírica de análise são os gabinetes parlamentares, e não os deputados como atores isolados. Para isso, a partir dos resultados do questionário, iremos criar e apresentar dois índices: de comunicação interna e de comunicação externa. Depois disto, iremos agregar estes índices em uma tipologia da comunicação de gabinete, para compreender como os gabinetes utilizam de forma distinta tais ferramentas e iremos cruzar os resultados encontrados com os partidos políticos dos respondentes, a fim de verificar se essa associação ajuda a explicar as distintas formas encontradas. Por fim, iremos apresentar nossa conclusão sobre as associações existentes entre os diferentes tipos de comunicação desenvolvidos pelas assessorias parlamentares e os partidos políticos representados na Câmara dos Deputados.

\section{Parlamentares e mídias sociais}

Ao tratar sobre o parlamento e o uso de mídias sociais, podemos identificar, grosso modo, distintas linhas e objetos de pesquisa. Parcela considerável das pesquisas desenvolvidas sobre essa temática abrange, especialmente, a utilização das mídias sociais em campanhas políticas majoritárias. Esses trabalhos analisam os padrões de uso por parte do candidato e procuram dimensionar as estratégias de comunicação utilizadas e a interação entre candidatos e eleitores (AGGIO, 2011, 2013; DRUCKMAN et al., 2009; CERVI; MASSUCHIN，2011; GIBSON; MCALLISTER， 2011; MARQUES \& SAMPAIO, 2011; MARQUES, SILVA \& MATTOS, 2013; MASSUCHIN e TAVARES, 2018; ROSSETTO et al., 2012). Outras pesquisas buscam avaliar a crescente utilização de ferramentas de participação e engajamento pelos parlamentos e atores parlamentares fora do período eleitoral, no período da legislatura parlamentar ordinária (FARIA, 2013; LESTON-BANDEIRA \& BRUM, 2017; BARROS, BERNARDES \& REHBEIN, 2016). 
É cada vez mais patente que, através da utilização de canais em redes tais como YouTube, Flickr, Instagram, Twitter ou Facebook, por exemplo, busca-se estimular o engajamento com o grande número de usuários dessas plataformas, o que ocorre tanto pelos representantes individuais como pelas instituições parlamentares como um todo. Ou seja, recursos que antes eram comuns apenas entre os usuários mais entusiastas da Web passam a ser utilizados no jogo político para aumentar a visibilidade de um indivíduo, partido ou instituição (MARQUES et al., 2013).

A utilização desses meios por parte de representantes e instituições não pode ser explicado sem levar em conta a dimensão estratégica da comunicação política, pois mesmo nessas plataformas permanece a lógica da disputa por visibilidade e gestão da imagem do agente e da instituição. Essas atividades necessitam conhecimentos específicos em diversas áreas que abrangem pesquisas de opinião, administração, publicidade, produção e criação, além de atualizações específicas para os diferentes meios de comunicação utilizados, sejam eles impressos, rádio, TV, sites, blogs e redes sociais. Cada vez mais esses trabalhos vêm sendo executados por profissionais da área a fim de atender às necessidades de comunicação política estratégica.Todo este movimento se insere dentro do que Wilson Gomes (2004) chamou de profissionalização da comunicação política. $\mathrm{O}$ autor argumentou que a emergência da consultoria profissional de comunicação, muito investigada em campanhas eleitorais (na era da ascensão dos "grandes marqueteiros"), não se restringiria às campanhas, mas, tendencialmente, também se estenderia às atividades dos eleitos.

Para Cristina Leston-Bandeira (2007), uma das peças-chave na análise do impacto da internet nos parlamentos são os assessores parlamentares (parliamentary staff), descritos como aos atores mais relevantes no processo de gatekeeping (seleção) da informação. Esta importância dos assessores no uso da internet pelos parlamentares é dupla. Primeiro, porque as decisões cotidianas do gerenciamento do mandato são tomadas, em grande parte, pelo staff, não pelo parlamentar. Isto é especialmente válido para o caso do uso das tecnologias digitais, em que existe certo aspecto "técnico". Segundo, porque as demandas que chegam via internet requerem volumes extras de atenção e informação circulando, que são designadas aos assessores. Vale conferir suas palavras:

A importância da assessoria parlamentar na implementação das tecnologias de comunicação e informação é dupla. Primeiro, embora políticos tenham a palavra final na elaboração de políticas públicas, a maior parte das decisões do dia-a-dia no gerenciamento do parlamento é tomada pelo corpo de assessoria parlamentar. E isto se aplica particularmente ao caso das tecnologias de informação e comunicação, uma área 


\begin{abstract}
"nova", de rápido desenvolvimento (difícil de seguir através do usualmente lento processo legislativo) e em que o status de expertise técnica contribui para fazer disto um domínio separado do "político". Em segundo lugar, porque as demandas trazidas através destes novos meios, em termos de lidar com grandes volumes de enquetes eletrônicas e circulação da informação, requer um suporte extra dado aos políticos. Portanto, tecnologias da informação e comunicação podem tornar as assessorias parlamentares muito mais cruciais no processo de filtrar, selecionar e interpretar informação. Como um de nossos assessores entrevistados confirmou, eles são um gatekeeper chave. (LESTONBANDEIRA, 2007b, p. 664, tradução livre) ${ }^{5}$
\end{abstract}

Este mesmo aviso já havia sido dado por França; Martins; Braga (2006), que realizaram um survey com os parlamentares paranaenses e apontam que eram raros os casos dos deputados que mantinham as próprias redes sociais digitais, sendo estas mantidas pelos funcionários do gabinete. Naquela ocasião, a maior parte dos deputados afirmava considerar a internet como ferramenta integrante do mandato, embora não tivessem a expertise necessária para se concentrar na manutenção destas ferramentas. Os autores apontaram, assim, para a necessidade de investigar não apenas os parlamentares, em si, mas os gabinetes e seus assessores. Em suma, a estrutura por detrás daquilo que chega aos cidadãos, aquilo que organiza o processo de representação política.

Com a exceção de importantes estudos sobre profissionalização de campanhas eleitorais (ABBE; HERRNSON, 2003; MEDVIC; LENART, 1997; NEGRINE et al., 2007; PANAGOPOULOS, 2006; THURBER, 1998), poucas pesquisas olharam para a equipe que coordena o processo comunicacional, elo entre parlamentar e cidadão. Gibson et al (2003), analisando eleições norte-americanas e britânicas, utilizam um survey, aliado à análise de conteúdo dos websites, para questionar a importância que os estrategistas de campanha davam à internet naquela ocasião - à época, constatando a baixa relevância atribuída às ferramentas online. Dai \& Norton (2007) realizam 40 entrevistas semiestruturadas com parlamentares e assessores, em busca de dados qualitativos sobre suas atividades online. Em outra oportunidade, Leston-Bandeira (2007a) apresenta os resultados de uma pesquisa com o staff parlamentar português, conduzida por meio de entrevistas, surveys presenciais e websurveys, sobre as percepções dos parlamentares acerca da atividade online.

O suíço Thomas Winzen, analisando os assessores técnicos do Parlamento

\footnotetext{
5 No original: "The importance of parliamentary staff in the implementation of ICT is two-fold. First, although politicians may have the final say on policymaking, most of the day-to-day decisions on the management of parliament is taken by parliamentary staff. And this applies particularly to the case of ICT, a 'new' area, of rapid development (difficult to follow through the commonly slow political process) and where the 'technical expert' status contributes to make it a realm separate from the 'political'. Secondly, because the demands brought in through these new media, in terms of dealing with high volumes of e-queries and circulation of information, require extra support given to politicians. So, ICT can make parliamentary staff all the more crucial in the process of sifting, selecting and interpreting information. As one of our interviewed support staff confirmed, they are a key 'gate-keeper'."
} 
Europeu, afirmou: "Enquanto já aprendemos bastante sobre a influência dos parlamentares, pouco se sabe sobre o papel de seus apoiadores não-eleitos (unelected supporters).”, isto é, os assessores parlamentares (WINZEN, 2011, p. 27, tradução livre) ${ }^{6}$. Não eleitos, sua função na conformação dos resultados legislativa é primordial - e nisto se incluem as formas comunicacionais que os gabinetes podem assumir.

\section{Desenho de pesquisa}

Como instrumento de pesquisa, foi aplicado um survey, presencial e amostral, aos gabinetes dos deputados federais da Câmara dos Deputados. O campo foi realizado durante o mês de novembro de 2014, contemplando a 54 a legislatura da Câmara dos Deputados. Todos os questionários foram elaborados e aplicados pelos próprios autores do artigo . O questionário foi aplicado ao assessor de comunicação responsável pelas mídias sociais em cada gabinete, não ao parlamentar em si. Desta forma, temos por universo 513 indivíduos, já que a unidade de análise é o gabinete e o assessor responsável por esta área. O questionário foi dividido em dois blocos (perfil dos funcionários do gabinete e comunicação do gabinete), totalizando 30 questões. Como diversas perguntas pediam múltiplas respostas, ao fim totalizaram-se 76 variáveis no banco de dados. Como a aplicação do questionário foi presencial, reduz-se o risco de viés favorável aos usuários de tecnologias digitais.

A amostra é composta por 144 respostas ( $28 \%$ do universo). Todos os estados e regiões estão representados na mesma proporção ou em proporção muito próxima àquela existente na Câmara. O quadro a seguir apresenta os dados comparativos entre nossos respondentes, estratificados por região e partido, e o universo. Dado o alto número de respondentes que obtivemos, esta amostra está distribuída de forma normal e representativa ${ }^{7}$. Apenas para exemplificar em termos comparativos, a última Pesquisa Legislativa Brasileira (POWER; ZUCCO JR., 2011), de 2009, sob coordenação de Timothy Power, tinha um N de 139 para as duas Casas do Congresso - esta tem 144 apenas para a Câmara. Em fato, todos os partidos brasileiros presentes na Câmara dos Deputados estão representados em nossa amostra de maneira quase idêntica à encontrada no parlamento.

\footnotetext{
${ }^{6}$ No original: "While much has been learned about the influence of parliamentarians, little is known of the role of their unelected supporters"

${ }^{7}$ Margem de erro de 5,35\%, a 90\% de nível de confiança
} 


\section{Quadro 1 - Descritivos da amostra e universo}

\begin{tabular}{|c|c|c|c|c|}
\hline & \multicolumn{2}{|c|}{ No universo } & \multicolumn{2}{|c|}{ Na amostra } \\
\hline & Número & Porcentual & Número & Porcentual \\
\hline \multicolumn{5}{|l|}{ Região } \\
\hline Norte & 65 & 12,7 & 21 & 14,6 \\
\hline Nordeste & 151 & 29,4 & 42 & 29,2 \\
\hline $\begin{array}{l}\text { Centro- } \\
\text { oeste }\end{array}$ & 41 & 8 & 13 & 9 \\
\hline Sudeste & 179 & 34,9 & 44 & 30,6 \\
\hline Sul & 77 & 15 & 24 & 16,7 \\
\hline Total & 513 & 100 & 144 & 100 \\
\hline \multicolumn{5}{|l|}{ Partidos } \\
\hline DEM & 28 & 5,5 & 8 & 5,6 \\
\hline PCdoB & 15 & 2,9 & 4 & 2,8 \\
\hline PDT & 18 & 3,5 & 7 & 4,9 \\
\hline PMDB & 71 & 13,8 & 24 & 16,7 \\
\hline PMN & 3 & 0,6 & 1 & 0,7 \\
\hline PP & 40 & 7,8 & 9 & 6,3 \\
\hline PPS & 6 & 1,2 & 1 & 0,7 \\
\hline PR & 31 & 6 & 11 & 7,6 \\
\hline PRB & 10 & 1,9 & 4 & 2,8 \\
\hline PROS & 20 & 3,9 & 3 & 2,1 \\
\hline PRP & 2 & 0,4 & 1 & 0,7 \\
\hline PSB & 25 & 4,9 & 5 & 3,5 \\
\hline PSC & 12 & 2,3 & 4 & 2,8 \\
\hline PSD & 45 & 8,8 & 11 & 7,6 \\
\hline PSDB & 45 & 8,8 & 12 & 8,3 \\
\hline PSOL & 3 & 0,6 & 2 & 1,4 \\
\hline PT & 87 & 17 & 24 & 16,7 \\
\hline РTB & 18 & 3,5 & 4 & 2,8 \\
\hline PTdoB & 3 & 0,6 & 1 & 0,7 \\
\hline PV & 8 & 1,6 & 2 & 1,4 \\
\hline SD & 22 & 4,3 & 6 & 4,2 \\
\hline S/ PART. & 1 & 0,2 & & \\
\hline Total & 513 & 100 & 144 & 100 \\
\hline
\end{tabular}

Fonte: Os autores

Como se percebe, em relação aos principais partidos políticos na arena eleitoral brasileira, PT, PMDB e PSDB, enquanto no universo eles têm, respectivamente, 17\%, $13 \%$ e $8 \%$ dos deputados federais que estavam ativos no mandato no momento em que aplicamos o survey, entre nossos respondentes estão distribuídos, também 
respectivamente, em $16 \%, 16 \%$ e $8 \%$. Isto é, a amostra representa com exatidão o universo de PSDB e PT e está apenas três pontos sobre-estimada para o PMDB (aliás, a maior distância entre amostra e universo entre todos os elementos e em um patamar que se encontra perfeitamente dentro do limite aceitável).

Na seção final do artigo, iremos utilizar os partidos políticos para cruzar com os resultados obtidos. Neste momento, será preciso agregar alguns partidos, como os partidos de esquerda e os partidos de direita, em prol de resultados estatísticos mais robustos, uma vez que os cruzamentos com frequências muito baixas (como $\mathrm{N}=<5$ ) não possuiriam relevância estatística. A agregação baseada na proximidade políticoideológica dos partidos segue as indicações existentes na literatura sobre o tema (POWER; ZUCCO JR., 2011). Mantivemos desagregados os maiores partidos brasileiros, de maior interesse do ponto de vista analítico.

$\mathrm{Na}$ segunda parte do artigo, pretendemos propor um índice e uma tipologia de comunicação dos gabinetes. No questionário, existem quatro questões diferentes sobre "comunicação de gabinete". Todas pedem para o respondente designar, em escala, a importância atribuída a uma série de ferramentas de comunicação, tanto tradicionais quanto de novas mídias. Duas questões se referem à comunicação externa (contato com cidadãos e divulgação em período eleitoral) e outras duas a comunicação interna (fonte de informações e gerenciamento do mandato). A partir da média do somatório das respostas chegamos, primeiro, a dois índices - de comunicação externa e de comunicação interna - que variam, potencialmente, de -5 (totalmente tradicional) a 5 positivo (totalmente mídias digitais). Com isto, poderemos verificar o grau de importância que é atribuído às ferramentas, comparativamente.

Depois disso, combinamos os dois índices em uma tipologia geral para a comunicação de gabinete, levando em conta o uso informado por cada respondente. Desta forma, temos nove tipos possíveis, que seguem apresentados no quadro abaixo.

\section{Quadro 2 - Tipologias de comunicação de gabinete}

\begin{tabular}{|l|l|l|}
\hline $\begin{array}{l}\text { Tipo 1. Externa } \\
\text { Tradicional; Interna } \\
\text { Tradicional. }\end{array}$ & $\begin{array}{l}\text { Tipo 2. Externa } \\
\text { Tradicional; Interna } \\
\text { Equilibrada }\end{array}$ & $\begin{array}{l}\text { Tipo 3. Externa } \\
\text { Tradicional; Interna } \\
\text { Digital }\end{array}$ \\
\hline Tipo 4. Externa & Tipo 5. Externa & Tipo 6. Externa \\
Equilibrada; Interna & Equilibrada; Interna & Equilibrada; Interna \\
Tradicional & Equilibrada & Digital \\
\hline Tipo 7. Externa & Tipo 8. Externa & Tipo 9. Externa \\
Digital; Interna & Digital; Interna & Digital; Interna Digital \\
Tradicional & Equilibrada & \\
\hline
\end{tabular}


Fonte: os autores

Esta tipologia nos permitirá mapear as modalidades possíveis de gerenciamento das mídias sociais pelos gabinetes parlamentares, bem como associar essas modalidades às diferentes características dos atores políticos representados na Câmara dos Deputados.

\section{Resultados}

\subsection{O uso das ferramentas de tecnologia digital na rotina interna dos gabinetes}

A tabela 1 sintetiza a taxa de respostas para duas questões: a avaliação sobre a importância destas ferramentas para o gerenciamento do mandato e a percepção sobre os impactos destas ferramentas na rotina parlamentar nos últimos dez $\operatorname{anos}^{8}$.

Tabela 1 - Auto percepção sobre importância e impacto das tecnologias digitais

\begin{tabular}{lc|c}
\hline & $\begin{array}{l}\text { Importância tecnologias p/ } \\
\text { gerenciamento mandato }\end{array}$ & $\begin{array}{l}\text { Intensidade tecnologias } \\
\text { alteraram exercício mandato }\end{array}$ \\
\cline { 2 - 3 } Muito baixo & $2,1 \%$ & $2,1 \%$ \\
Baixo & $1,4 \%$ & $2,8 \%$ \\
Médio & $6,9 \%$ & $11,1 \%$ \\
Alto & $22,9 \%$ & $29,9 \%$ \\
Muito alto & $63,9 \%$ & $51,4 \%$ \\
Total & $97,2 \%$ & $97,2 \%$ \\
\hline Missing & $2,8 \%$ & $2,8 \%$ \\
\hline
\end{tabular}

Fonte: Elaboração própria.

Esta questão é importante, pois mostra que, ainda que o parlamentar não deseje ser accountable perante sua base eleitoral, e, portanto, não estabeleça canais de comunicação na internet com o cidadão, isto não significa que as tecnologias digitais e mesmo as mídias sociais não tenham impacto sobre o gabinete. O impacto existe, também, nos aspectos da rotina interna que apresentamos aqui. Em termos gerais acerca deste tópico, percebem-se evidências de que estas tecnologias impactam não somente as relações externas ao gabinete (sua importância como comunicação), mas a sua própria rotina de trabalho.

A questão seguinte investiga as motivações para se estar online. Um dos debates

\footnotetext{
${ }^{8}$ Entretanto, não é em todos aspectos que tais tecnologias se destacam. Adicionalmente, perguntamos sobre o suporte dado pela Casa para o uso da internet e das mídias sociais (conexão, treinamento aos assessores etc.), os respondentes manifestaram certa insatisfação. A tabela com as frequências simples se encontra nos apêndices.
} 
da literatura sobre mídias digitais questiona os motivos por que os parlamentares estão online, o que leva, inclusive, a boa parte da literatura se debruçar em análise de conteúdo sobre o comportamento online destes atores, a fim de verificar qual tipo de conteúdo produzem. Pedimos para nossos respondentes elencarem a ordem de importância dessas motivações. Os resultados estão no gráfico 3. Todos valores deste e dos gráficos seguintes referem-se à porcentagem, não à porcentagem válida. Portanto, os valores podem fechar com menos de $100 \%$, caso existam valores ausentes (alguns respondentes que tenham deixado um ou outro item não-respondido).

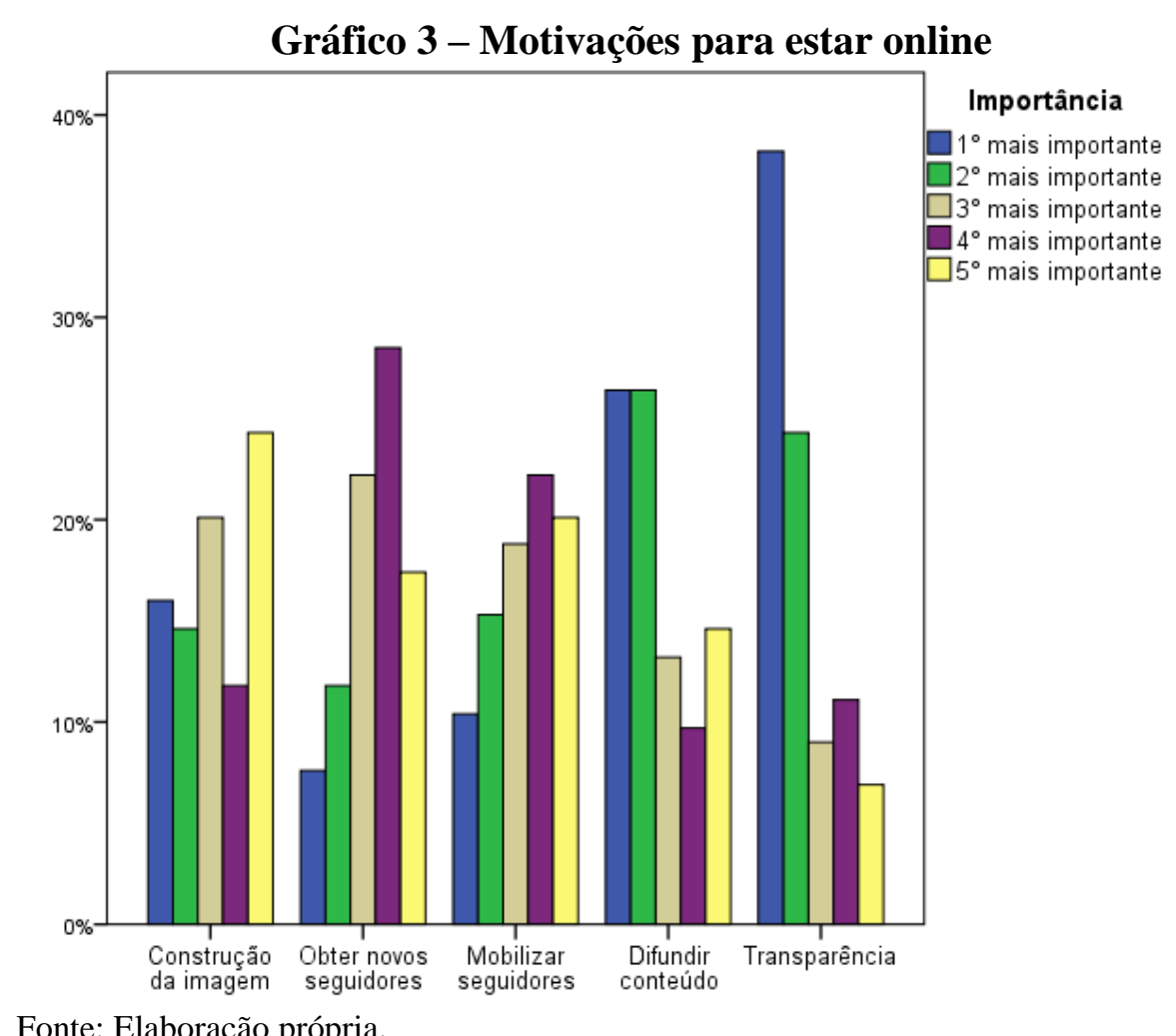

Fonte: Elaboração própria.

A primeira questão a notar é que 37,9\% afirmaram "gerar transparência" ser o principal motivo para estar online. Somado aos $24,1 \%$ que afirmaram esta ser a segunda causa, tal item atinge impressionantes $62,1 \%$. Além de demonstrar que os atores consideram que a transparência é um elemento importante para ser externado - acreditem eles nisto ou não, ou seja qual for sua concepção de "transparência", o que não temos como saber com este instrumento de pesquisa - a questão está relacionada a gerar informações sobre os deputados e suas atividades, produzidas pelos próprios mandatos. A partir do momento em que eles "geram transparência" divulgando suas posições públicas, votações, gastos etc., passam a ser proativos frente a um universo midiático 
ávido por informações, podendo divulgar estas informações do modo que melhor lhes sirva. A evidência também corrobora a tese de Coleman (2005) de "representação direta", uma vez que as assessorias buscam um contato direto com os cidadãos, de forma mais independente da mídia ou das máquinas partidárias

Das cinco opções apresentadas, a mais frutífera em termos analíticos é a distinção entre mobilizar seguidores ou conquistar novos seguidores. Neste ínterim, podemos dialogar com a literatura que debate se os políticos usam tais plataformas para falar somente aos já convertidos (NORRIS, 2003) ou se falam com estes como meio para atingir novos adeptos (VISSERS, 2009).

Percebe-se que as duas questões estão muito próximas em grau de importância atribuído pelos políticos, embora mobilizar seguidores esteja à frente, somando $25,5 \%$ entre primeira e segunda mais importantes funções, contra 19,3\% de conquistar novos seguidores, na mesma soma.

A seguir, buscamos descobrir os tipos de feedback que os políticos obtêm de seus seguidores, online. Saber que tipo de feedback, de interação, os políticos recebem é analiticamente importante. Recentemente, a pesquisa de Carlomagno, Braga e Sampaio (2018) buscou verificar quais tipos de mensagens os parlamentares respondem mais ou menos, constatando que, além de eles responderem mais via mídias sociais do que via email, eles tendem a responder mais a mensagens amigáveis, com apoio eleitoral, do que a mensagens que cobrem questões sobre comportamento legislativo (como o deputado teria votado em dada questão). Um analista do comportamento externado, isto é, do comportamento público, poderia medir reações positivas ou negativas por meio de comentários às postagens, mas esta é uma perspectiva limitada, pois não nos dá as interações que ocorrem privadamente, em mensagens trocadas entre os usuários e as páginas. Essas interações só são acessíveis pelo meio que utilizamos, o survey com os operadores do sistema. Portanto, este é outro ponto de destaque desta pesquisa.

\section{Gráfico 4 - Tipos de feedback recebidos}




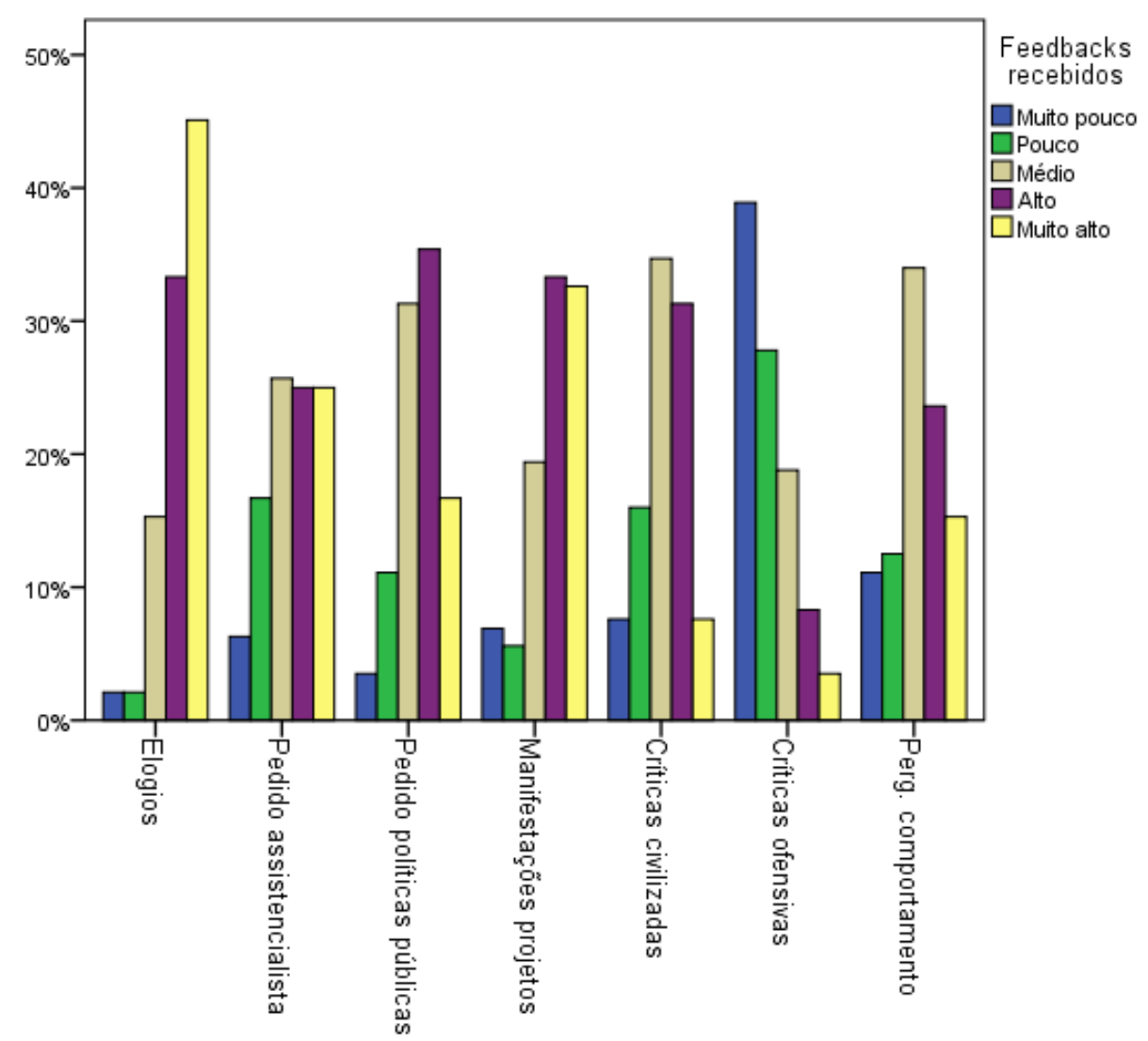

Fonte: Elaboração própria.

Primeiramente, é preciso ponderar alguns aspectos encontrados, por exemplo, as taxas altas para elogios e baixas para críticas. Embora talvez isto ocorra devido ao viés do respondente (o que é possível que tenha ocorrido e precisamos considerar), tal tendência faz sentido lógico, se pensarmos que o cidadão indignado disposto a fazer críticas ofensivas ao deputado, usualmente o faz de forma pública, nos comentários, e não em privado, nas mensagens. Ainda assim, o nível de críticas civilizadas é alto. Ou seja, os respondentes não estão negando que receberam críticas. Outro possível fator explicativo é que se trata de parlamentares, que, salvo raros casos, não atraem paixões e ódios do cidadão mediano, como usualmente ocorre em cargos executivos. A baixa atenção que os cidadãos dão aos representantes legislativos no Brasil ocorre, em boa parte, pela natureza do sistema eleitoral brasileiro. Uma vez que cargos legislativos (à exceção do Senado) são eleitos por sistema proporcional com alta magnitude, a memória eleitoral do cidadão - e, consequentemente, a possibilidade de accountability - é muito baixa (CAREY, 2016). Eleitos por cargos majoritários, por outro lado, tendem a ser mais lembrados e cobrados pelos cidadãos.

A distinção que talvez seja mais frutífera em termos analíticos é entre pedidos de políticas públicas e os pedidos assistencialistas, em que a taxa de resposta do primeiro se 
sobrepõe ao segundo. Aqui, é preciso considerar dois fatores na explicação. Primeiro, o que seria a explicação mais sedutora para aqueles que acreditam no poder transformador da internet, é que o ambiente virtual é constituído de uma nova prática de democracia digital, em que os sujeitos estão mais preocupados com políticas públicas do que em bens para si. A segunda explicação é mais racional, em termos de qual é o estrato da sociedade que utiliza mídias sociais, em geral, e qual estrato tenta contactar políticos. Um terceiro aspecto a considerar é que não conseguimos ter acesso, pelo questionário, a qual sentido é dado pelos respondentes a cada termo. Por exemplo, um constituency service, como conseguir o asfalto para uma rua ou a melhoria de um hospital, é uma política localista, análogo ao tipo pork-barrel, mas talvez seja interpretada como uma política pública pelo respondente.

Por fim, nesta seção, verificamos a importância atribuída às ferramentas de comunicação, que podem ser utilizadas tanto externamente - para contato com os cidadãos - quanto internamente. Neste tópico, examinamos a importância atribuída pelos assessores a uma série de ferramentas, em quatro esferas distintas: a) no contato com os cidadãos; b) como divulgação das ações à base eleitoral (perspectiva eleitoral); c) como fonte de informações do gabinete; d) da importância para o gerenciamento do mandato.

As duas primeiras dizem respeito à comunicação externa, com os cidadãos, ao passo que as duas últimas se referem à comunicação interna do gabinete. Primeiramente, apresentamos os resultados globais de cada ferramenta, nos gráficos 5 a 8 . Na seção seguinte, faremos uso destas respostas para criação de um índice, a fim de dar maior compreensibilidade e concisão aos resultados.

\section{Gráfico 5 - Importância das ferramentas no contato com cidadãos}




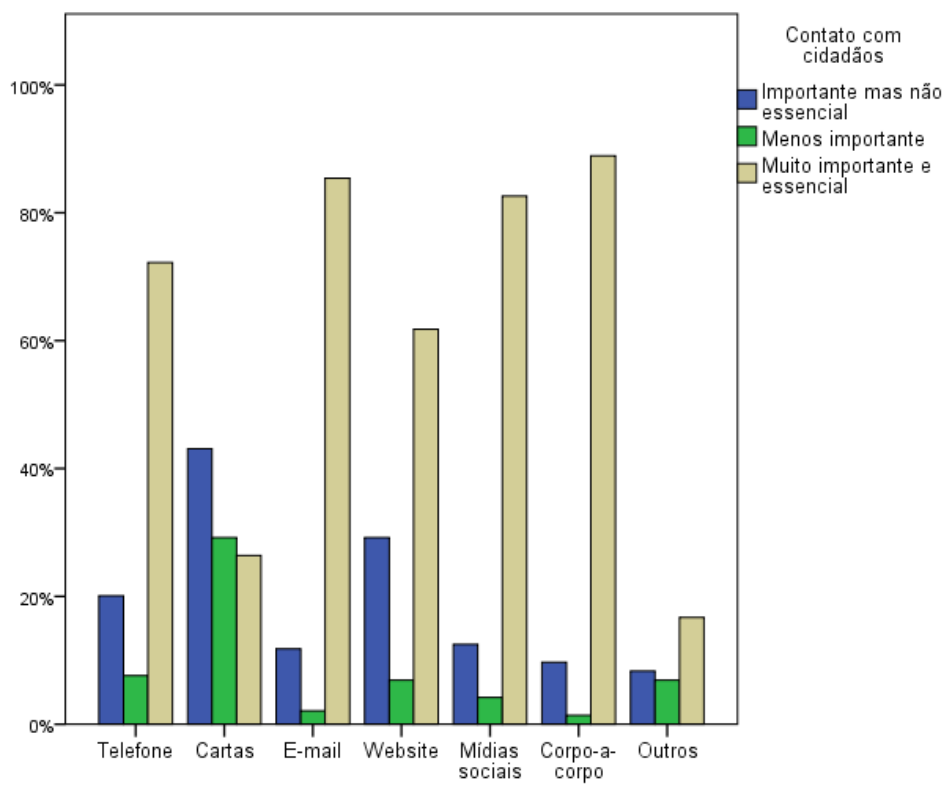

Fonte: Elaboração própria.

\section{Gráfico 6 - Uso das ferramentas para divulgar ações junto às bases eleitores}

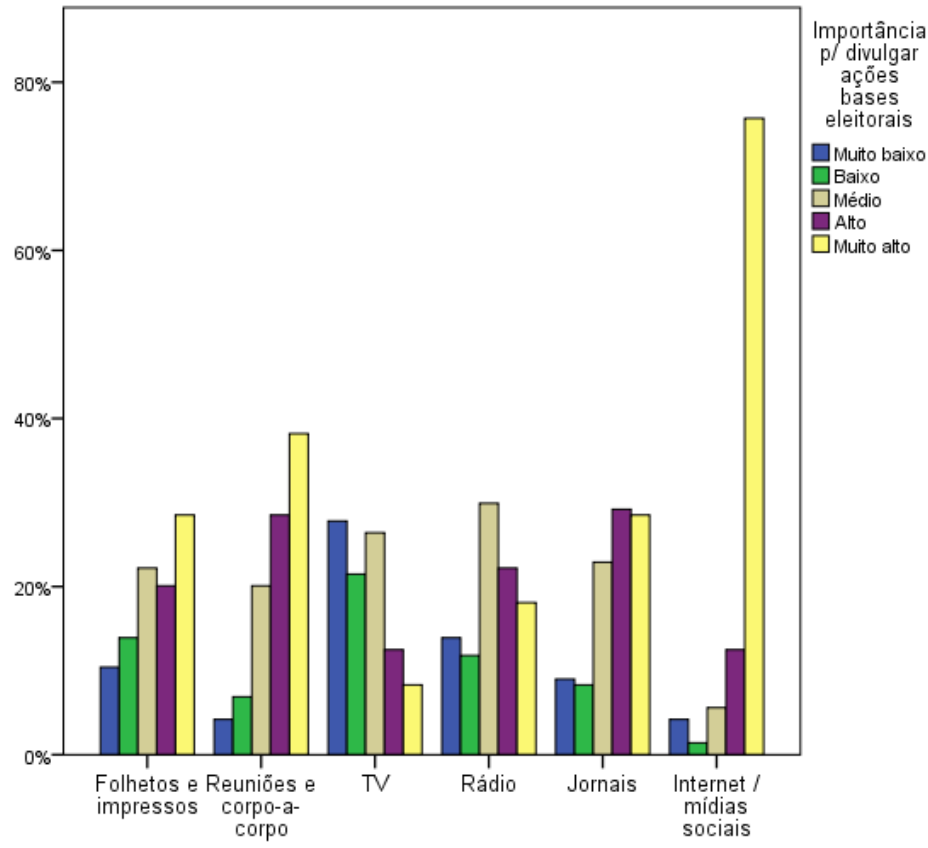

Fonte: Elaboração própria. 
Gráfico 7 - Papel das ferramentas como fonte de informação para o gabinete

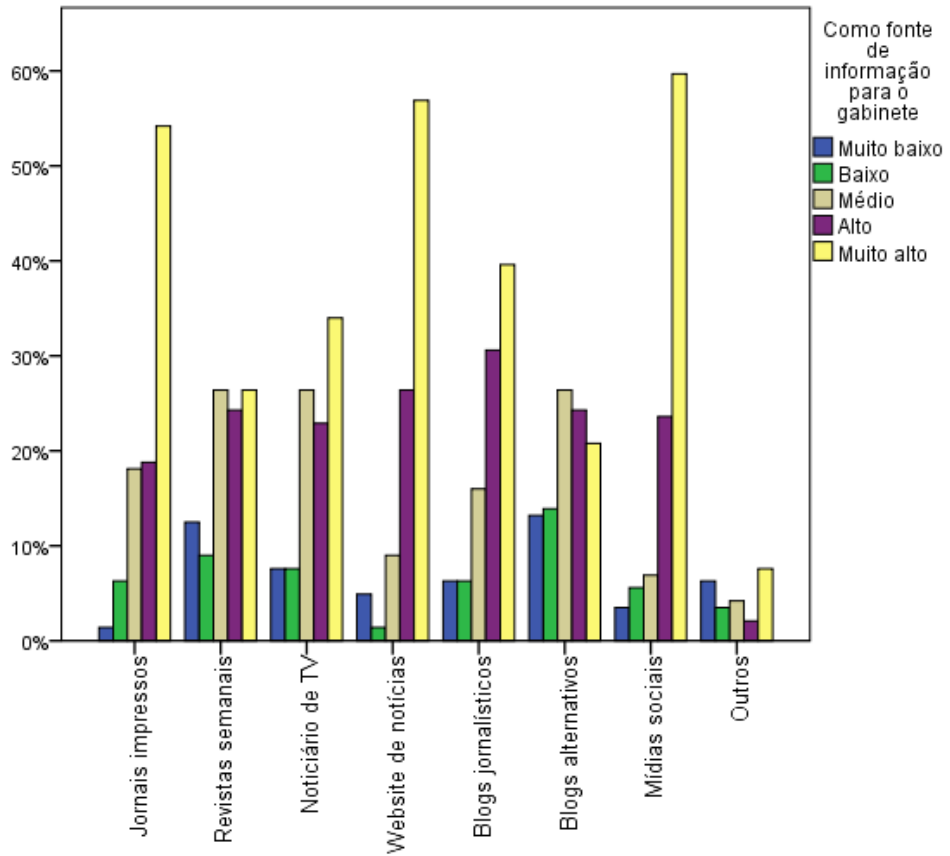

Fonte: Elaboração própria. 


\section{Gráfico 8 - Importância das ferramentas para o gerenciamento do mandato}

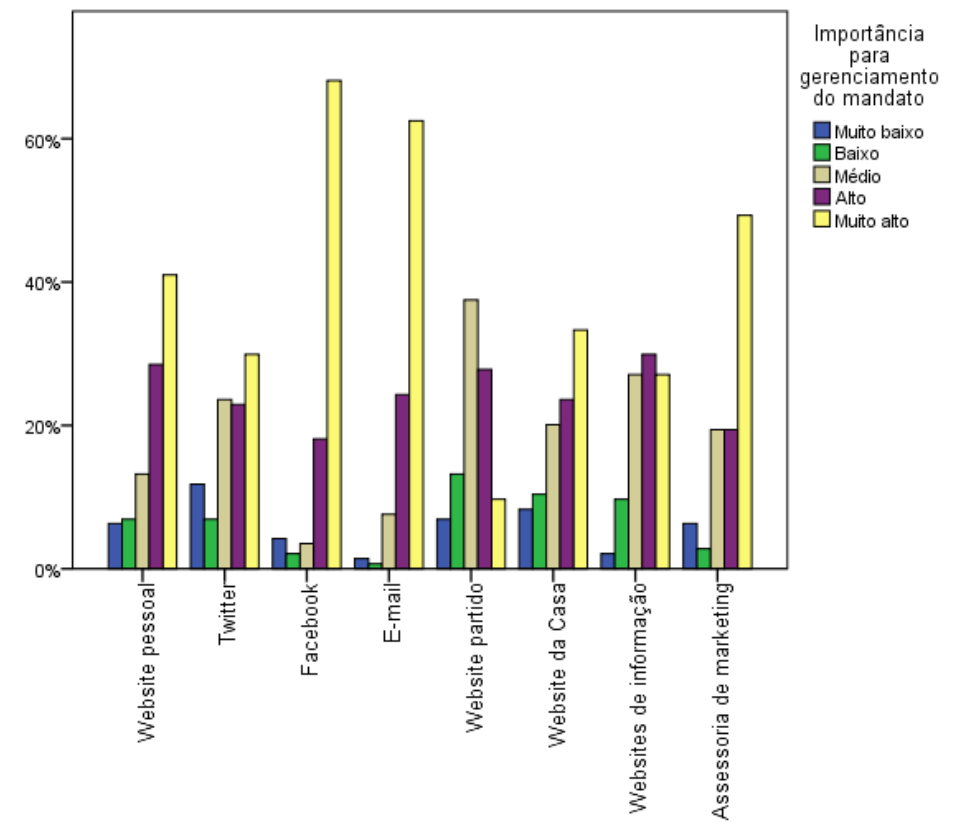

Fonte: Elaboração própria.

Como se percebe, em todas as categorias as mídias sociais detêm um papel muito elevado, segundo a percepção dos respondentes. No gráfico sobre o gerenciamento do mandato, percebe-se que os websites dos parlamentares ainda são considerados muito importantes - informação que vai no sentido oposto àquele demonstrado pela literatura mais recente, que aponta a sua cada vez menor utilização. Esta é uma interessante evidência adicional ao caráter personalizado da representação política no Brasil, na medida em que websites partidários e institucionais são colocados em segundo plano. Contudo, quando questionados acerca do contato com os cidadãos, apenas $63 \%$ considera o website imprescindível, diante de $86 \%$ que assim consideram o e-mail e $83 \%$, as mídias sociais - corpo-a-corpo, compreensivelmente, ainda é o meio considerado mais importante, por $89 \%$ dos respondentes.

Na seção seguinte, utilizaremos estas informações para sintetizar um índice que dê maior inteligibilidade às práticas comunicativas dos gabinetes.

\section{2 Índice de comunicação externa e interna}

A partir das quatro questões de nosso questionário que dizem respeito à avaliação das ferramentas de tecnologias digitais, propomos dois índices, um para comunicação interna e outro para a comunicação externa, conforme explicada na seção desenho de pesquisa. Nos dois índices (de comunicação externa e de comunicação interna), 
agregamos o valor atribuído a cada ferramenta entre tradicionais (ou não digitais) e comunicação online. Os valores negativos se referem às ferramentas não-digitais e os positivos às digitais; valores próximos a zero mostram equilíbrio. $\mathrm{O}$ gráfico 9 mostra o cruzamento dos dois índices.

\section{Gráfico 9 - Relação entre os índices de comunicação interna e externa}

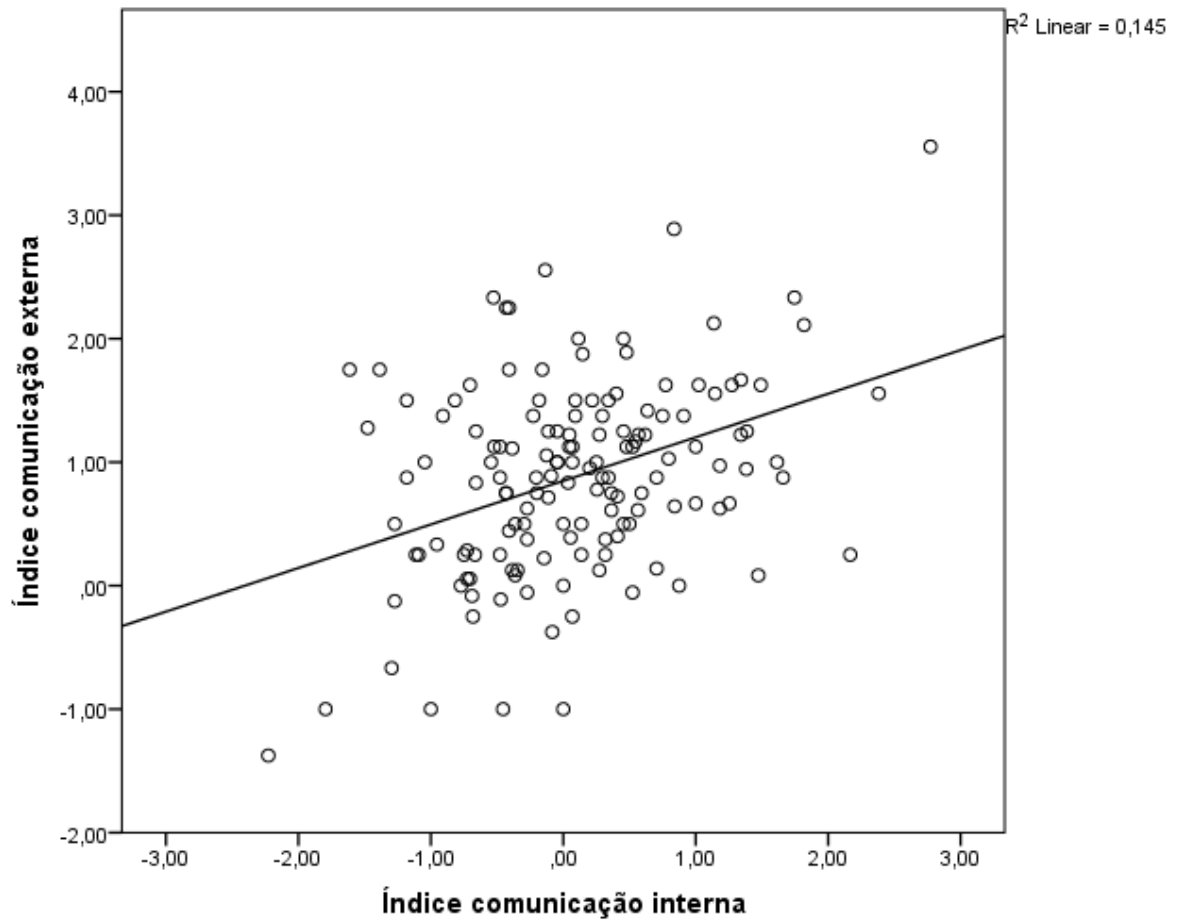

Fonte: Elaboração própria.

A correlação de Pearson entre os dois índices é de 0,381 (sig=0,000). Isto indica que há apenas uma correlação moderada entre os dois tipos de comunicação. Ou seja, a relação lógica que poderia ser esperada entre quem usa mais a tecnologia externamente e quem usa mais internamente e vice-versa não costuma ocorrer. Os dois pontos nas extremidades superior direita e inferior esquerda são exemplos do que seria essa relação lógica: o primeiro caso usa muito as tecnologias digitais nos dois âmbitos e o segundo usa meios tradicionais nos dois tipos de comunicação. Contudo, casos no quadrante superior esquerdo utilizam a comunicação externa digital, mas interna tradicional. Assim como os casos no quadrante direito inferior, curiosamente, utilizam muito a tecnologia na comunicação interna, mas não consideram essas ferramentas tão importantes na comunicação externa. Isto, por si só, já mostra a relevância do framework (modelo analítico) proposto por este artigo. Uma vez que não há relação perfeita dos dois tipos de comunicação, um não pode servir como proxy (indicador indireto) do outro. Logo, a 
pesquisa sobre os aspectos internos da rotina parlamentar se faz premente.

\subsection{Associação com partidos políticos e tipologia do tipo de comunicação}

Verificamos nas seções anteriores a distribuição geral dos dados. Nesta seção, iremos verificar se os padrões detectados encontram relação com algum fator externo, que sirva como variável explicativa, isto é, que ajude a explicar as diferenças no comportamento político de cada um destes atores.

Embora a ciência política possa oferecer uma longa lista de variáveis explicativas, optamos, aqui, pelo cruzamento com o partido político dos parlamentares responsáveis pelos gabinetes, já que esta é uma variável clássica que ajuda a compreender, ao menos em parte, as distinções entre os comportamentos parlamentares - e, em tese, pode também ajudar a explicar as distinções existentes entre os diversos modos de organização dos gabinetes e suas práticas comunicativas.

Também nesta seção iremos apresentar a tipologia referente à comunicação dos gabinetes, conforme já apresentado na seção desenho de pesquisa, formada a partir dos índices de comunicação interna e externa.

Na seção anterior, investigamos as motivações dos respondentes para estar online. Mas, será que esta atribuição é equânime a todos partidos? A literatura nos ensina que, historicamente, tem existido distinções partidárias em relação ao comportamento destes na arena eleitoral e nas formas utilizadas para captar seus apoiadores. Portanto, seria lógico que existissem também distinções tanto no comportamento online quanto nestas motivações. A seguir, apresentamos no gráfico 10, dividido em partes, os valores das respostas por partidos. 
Gráfico 10 - Motivos para estar online, por partido
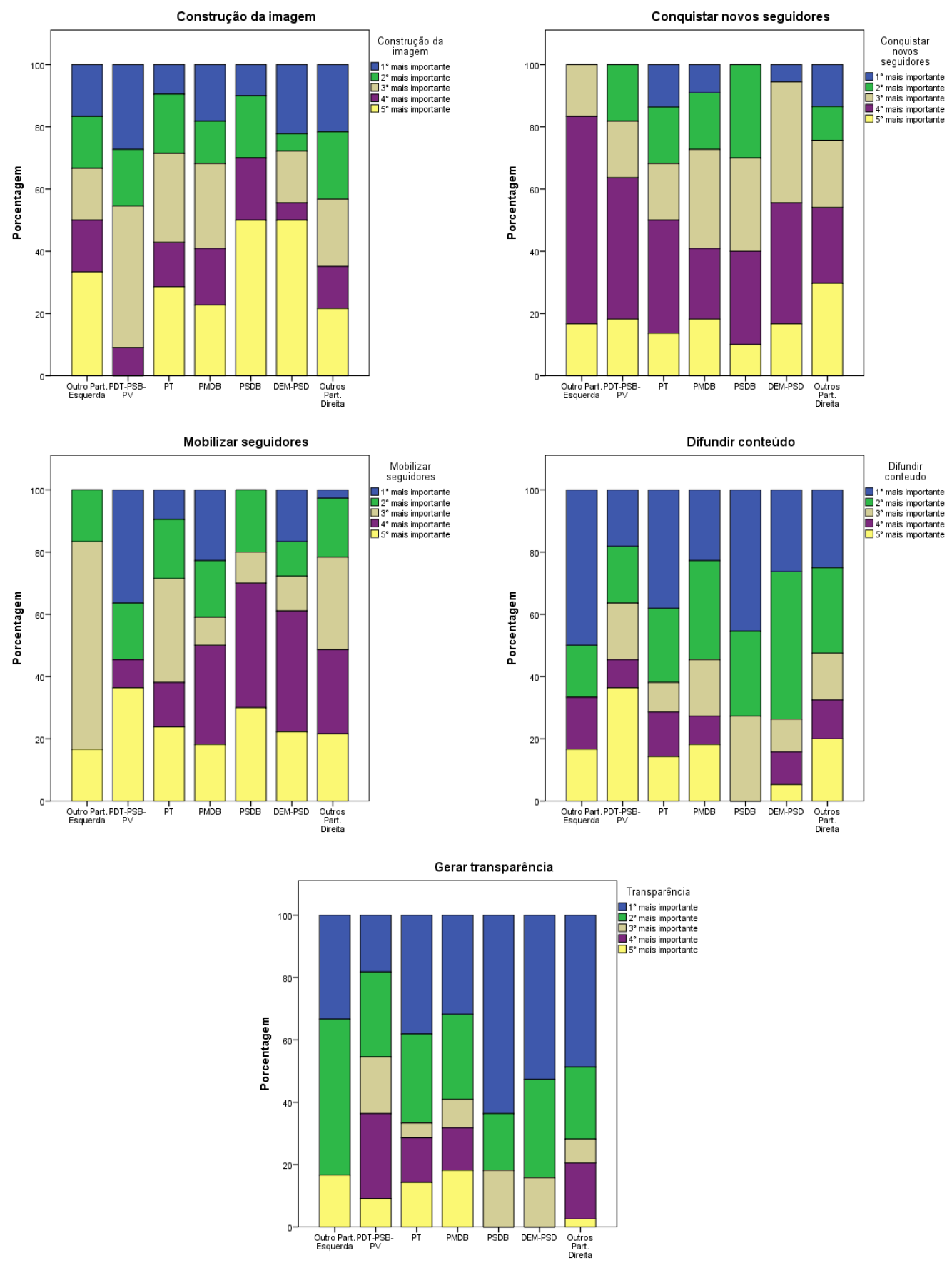

Fonte: Elaboração própria.

Podemos verificar no quadro partidário a questão entre mobilização de adeptos versus captação de novos simpatizantes. Neste tópico, percebemos que, para o PT, conquistar novos seguidores é levemente mais importante do que mobilizar os atuais. Em comparação com o PSDB e praticamente todos demais partidos, as duas questões referentes aos seguidores são muito mais importantes para o PT e o PMDB. Curiosamente, mesmo os outros partidos de esquerda - cujo público teoricamente é composto majoritariamente por seus filiados, por não serem partidos de grande expressão 
- a questão de mobilizar seguidores só aparece na terceira colocação mais importante.

Há uma distinção importante. PT e PSDB são os únicos partidos - considerando as duas primeiras colocações em importância - em que "conquistar novos seguidores" supera "mobilizar seguidores". Podemos considerar, então, que para os partidos centrais na arena eleitoral nacional é mais importante atingir novos eleitores, enquanto os partidos periféricos preferem pregar para os já convertidos. Uma lógica racional, não de cunho ideológico, rege o comportamento dos atores.

A seguir, com a combinação destes dois índices, apresentamos a tipologia de comunicação de gabinete proposta, conforme o quadro 2 , presente na seção desenho de pesquisa. Faremos, desde já, a relação com os partidos políticos. Neste gráfico, devido ao limite de espaço na imagem, designamos os tipos de comunicação pelo número do tipo.

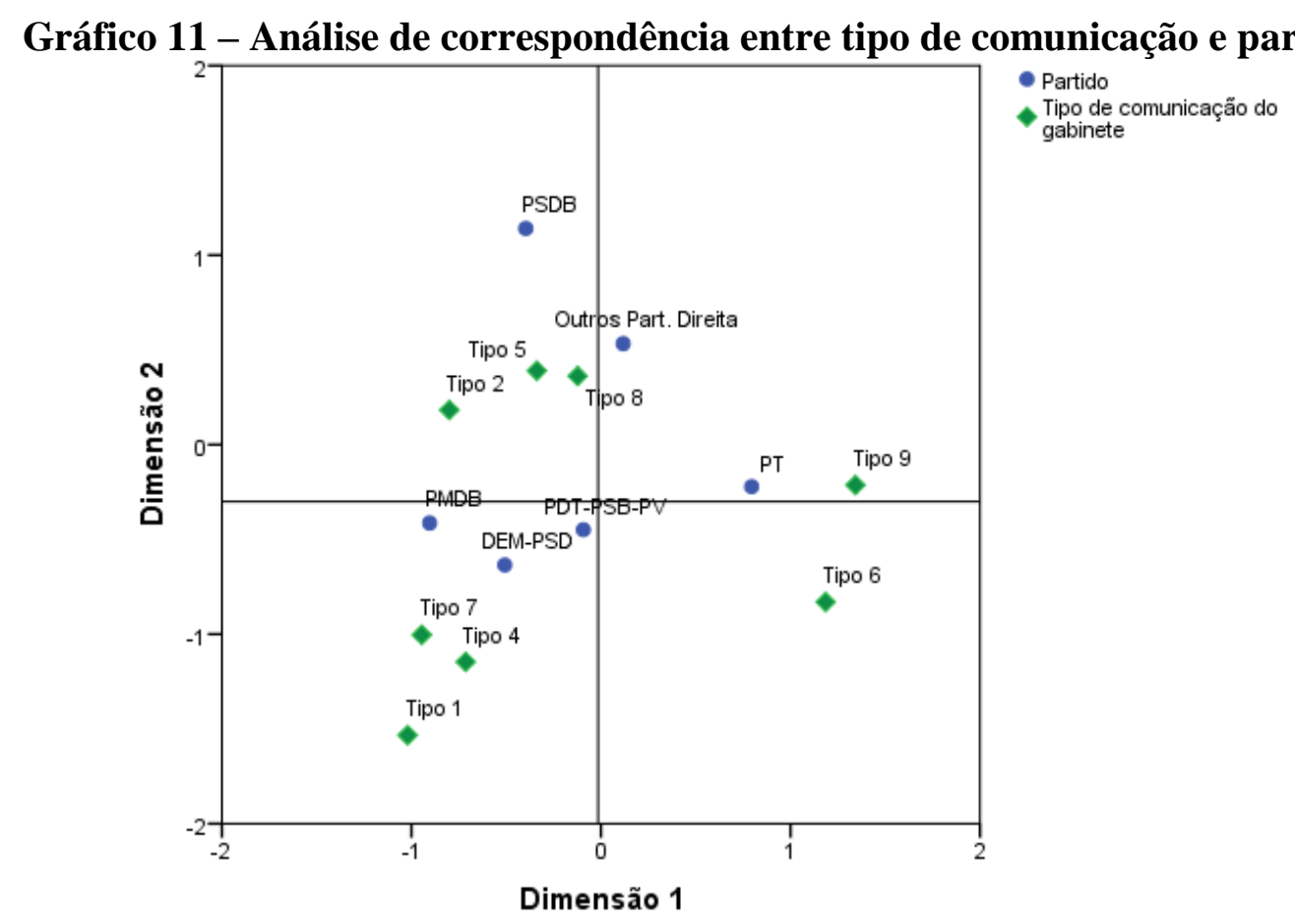

Fonte: Elaboração própria. os autores

Podemos perceber que o PT está mais próximo dos tipos 6 e 9. Isto é, o partido brasileiro mais próximo de um modelo de comunicação digital. Assim como também os outros partidos de esquerda estão muito próximos do tipo 9 , totalmente digitalizado. $\mathrm{O}$ bloco de centro-esquerda fica entre os tipos 1,4 e 5, isto é, de tradicional a um meiotermo - similar ao que ocorre com o bloco de centro-direita. O PSDB, embora apresente maior proximidade com o tipo 8 (identificado pelo teste de resíduos padronizados), isto é, também digitalizado, em todas as categorias seus valores se aproximam muito da 
distribuição normal.

Em resumo, o uso dos partidos políticos parece frutífero, ao menos em parte, para ajudar a distinguir os tipos de comunicação adotados pelos gabinetes parlamentares.

\section{Considerações finais}

Este artigo investigou a utilização de ferramentas digitais pelos gabinetes parlamentares na Câmara dos Deputados, a partir do ponto de vista daqueles que efetivamente operam essas ferramentas, isto é, as assessorias parlamentares trabalhando com comunicação nos gabinetes dos deputados federais, uma abordagem pouco explorada na literatura brasileira sobre internet e política. O pressuposto dessa análise é que o mandato não deve ser compreendido como algo exercido pelo deputado isoladamente. Ele é uma ação política desenvolvida em equipe, na medida em que exige uma ação coordenada de um corpo de funcionários que fornece uma estrutura de apoio para a atuação do parlamentar, o qual, naturalmente, é o ator central desse processo e, em última análise, detém a prerrogativa formal de deliberar sobre o curso de suas ações. Tal como Cristina Leston-Bandeira, entre outros, já havia apontado, a análise apresentou claro rendimento e potencial analítico.

A partir da mensuração realizada nas entrevistas com as assessorias, propusemos e apresentamos o índice de comunicação interna e externa, em que depreendemos as características da utilização dos meios mais tradicionais ao uso das ferramentas mais digitalizadas. Também apresentamos uma tipologia, criada partir desse índice. $\mathrm{O}$ índice e a tipologia podem ser objeto de outras pesquisas, em outros contextos, a fim de testar sua eficácia e eventual aprimoramento. Entre as contribuições desta pesquisa, destaca-se o uso das ferramentas avaliadas não apenas no contato com os cidadãos, mas na rotina interna dos gabinetes. As evidências sugerem que essas tecnologias impactam não somente as relações externas ao gabinete - sua importância como comunicação social -, mas a própria rotina interna de trabalho.

Ainda que exista, conforme afirma Marques et al. (2013), um claro aumento da apropriação de ferramentas de comunicação digital por parte dos gabinetes parlamentares, a análise por partidos mostra que há considerável variação no padrão de uso entre as agremiações políticas. Diferentes fatores podem explicar as diferentes formas de uso, um deles pode ser, como demonstrado no survey, a própria percepção que os gabinetes possuem das plataformas de comunicação como determinante para uma apropriação mais assídua de determinada estratégia de comunicação. 
Os achados aqui apresentados necessitam ser aprofundados com outras análise comparativas, tanto em nível subnacional, como envolvendo outras legislaturas do parlamento brasileiro, a fim de verificar se os dados aqui analisados constituem alguma tendência de longa duração em relação a uma maior profissionalização no uso das mídias digitais pelos assessores. Enquanto nos Estados Unidos o staff parlamentar tem atenção desde os anos 1980 (HAMMOND, 1984), tal objeto de pesquisa apenas muito recentemente têm ganhado espaço dentro das pesquisas sobre o legislativo. Acreditamos que este objeto é essencial tanto para compreender as dinâmicas do recorte específico sobre a utilização das ferramentas digitais pela elite política, quanto, em termos mais amplos, para outros temas e aspectos dentro da área de estudos legislativos.

\section{Referências}

ABBE, O. G.; HERRNSON, P. S. Campaign Professionalism in State Legislative Elections. State Politics \& Policy Quarterly, v. 3, n. 3, p. 223-245, 2003.

AGGIO, Camilo. As campanhas políticas no Twitter: uma análise do padrão de comunicação política dos três principais candidatos à presidência do Brasil em 2010. In: ENCONTRO DA ASSOCIAÇÃO BRASILEIRA DOS PESQUISADORES EM POLÍTICA, IV, Rio de Janeiro, abril, 2011.

AGGIO, Camilo de Oliveira. Campanhas on-line: o percurso de formação das questões, problemas e configurações a partir da literatura produzida entre 1992 e 2009. In:

AGGIO, C.; MARQUES, F. P. J. A.; SAMPAIO, R. (Org.). Do clique à urna: internet, redes sociais e eleições no Brasil, Salvador: EDUFBA, 2013. p. 103-121.

BARROS, A. T. A internet como mídia política nos países lusófonos: análise dos websites dos parlamentos de língua portuguesa. Observatorio, v. 11, n. 3, 187-202, 2017.

BARROS, A. T., BERNARDES, C. B.;REHBEIN, M. R. Brazilian Parliament and digital engagement. The Journal of Legislative Studies, v. 22, n. 4 p. 540-558, 2016.

BARROS, A. T.; REHBEIN, M., BERNARDES, C. B; Brazilian Parliament and digital engagement. In: BERNARDES, Cristiane Brum; LESTON-BANDEIRA, Cristina, BRAGA, Ricardo de João (Org.). The Legislature of Brazil. London: Routledge, 2018 p. 96-114.

BERNARDES, C. B;BANDEIRA, C. L. Information vs Engagement in parliamentary websites-a case study of Brazil and the UK. Revista de Sociologia e Política, v. 24, n. 59, p. 91-107, 2016.

BRAGA, S.; CARLOMAGNO, M. Eleições como de costume? Uma análise longitudinal das mudanças provocadas nas campanhas eleitorais brasileiras pelas tecnologias digitais (1998-2016). Revista Brasileira de Ciência Política, n. 26, p. 7-62, 2018. 
CARLOMAGNO, M.C.; BRAGA, S.S.; SAMPAIO, R.C. Respondem os políticos a questionamentos dos eleitores? Um experimento controlando os incentivos de mensagem, período e meio. Opinião Pública, v. 24, n. 2, p. 328-364, 2018.

CAREY, J. M. Legislative accountability: should brazil break up its big electoral districts? E-Legis, v. 19, n. 1, p. 72-86, 2016.

CERVI, Emerson Urizzi; MASSUCHIN, Michele Goulart. O uso do twitter nas eleições de 2010: O microblog nas campanhas dos principais candidatos ao governo do Paraná. Contemporanea, v. 9, n. 2, p. 319-334, 2011.

COLEMAN, S. Direct Representation: Towards a Conversational Democracy. London: IPPR Exchange, 2005a.

COLEMAN, S. New mediation and direct representation: reconceptualising representation in the digital age. New Media and Society, v. 7, n. 2, p. 177-198, 2005b.

COLEMAN, S.; MOSS, G. Governing at a distance-politicians in the blogosphere. Information Polity, v. 13, n. 1-2, p. 7-20, 2008.

DAI, X.; NORTON, P. The Internet and Parliamentary Democracy in Europe. The Journal of Legislative Studies, v. 13, n. 3, p. 342-353, 2007.

FRANÇA, A. S. T.; MARTINS, F. R. S.; BRAGA, S. S. O impacto da internet no funcionamento das instituições representativas: o caso do Paraná. Mediações, v. 11, n. 2, p. 163, 2006.

HAMMOND, S. W. Legislative Staffs. Legislative Studies Quarterly, v. 9, n. 2, p. 271-317, 1984.

GIBSON, Rachel K. et al. Election Campaigning on the WWW in the USA and UK: A Comparative Analysis. Party Politics, v. 9, n. 1, p. 47-75, 2003.

GIBSON, Rachel K.; MCALLISTER, Ian. Do online election campaigns win votes? The 2007 Australian "YouTube" election. Political Communication, v. 28, n. 2, p. 227-244, 2011.

GOMES, W. Transformação da política na era da comunicação de massa. São Paulo: Paulus, 2004.

LESTON-BANDEIRA, C. Are ICTs Changing Parliamentary Activity in the Portuguese Parliament? The Journal of Legislative Studies, v. 13, n. 3, p. 403-421, $2007 a$.

LESTON-BANDEIRA, C. The Impact of the Internet on Parliaments: a Legislative Studies Framework. Parliamentary Affairs, v. 60, n. 4, p. 655-674, 2007 b.

LESTON-BANDEIRA, C. Towards a trustee model? Parliamentary representation in the internet era. The Portuguese case. Parliamentary Affairs, v. 65, p. 425-447, 2012. 
LILLEKER, D. G; KOC-MICHALSKA, K; SCHWEITZER, E. J.; JACUNSKI, M.; JACKSON, N.; VEDEL, T. Informing, engaging, mobilizing or interacting: Searching for a European model of web campaigning. European Journal of Communication, n. 26, 195-213, 2011.

LILLEKER, Darren; KOC-MICHALSKA, Karolina. Online Political Communication Strategies: MEPs, E-Representation, and Self-Representation. Journal of Information Technology \& Politics, v. 10, n. 2, p. 190-207, 2013.

MARQUES, F. P. J. A.; AQUINO, J. A. DE; MIOLA, E. Parlamentares, representação política e redes sociais digitais. Opinião Pública, v. 20, n. 2, p. 178-203, 2014.

MARQUES, F. P. J. A.; SILVA, F.; MATOS, N. MARQUES, Francisco Paulo Jamil Almeida; SILVA, Fernando Wisse Oliveira; MATOS, Nina Ribeiro. Estratégias de Comunicação Política Online: uma Análise do Perfil de José Serra no Twitter. Contemporânea, v. 9, n. 3, p. 344-369, 2012.

MARQUES, F. P. J. A.; SAMPAIO, R. C. Election after Election: Rupturas e continuidades nos padrões mediáticos das campanhas políticas online. In: ENCONTRO ANUAL DA COMPÓS, XX, Porto Alegre, 2011. Anais [...]. Porto Alegre: [s.n], 2011.

MASSUCHIN, Michele Goulart; TAVARES, Camilla Quesada. Dinâmicas da campanha online no Brasil: um estudo comparativo entre websites e fanpages dos candidatos à Presidência em 2014. Contemporanea, v. 16, n. 1, p. 333-357, 2018.

MEDVIC, S. K.; LENART, S. The Influence of Political Consultants in the 1992 Congressional Elections. Legislative Studies Quarterly, v. 22, n. 1, p. 61-77, 1997.

NEGRINE, R. "The Professionalisation of Political Communication in Europe". In. NEGRINE, R. et al. (Org.). The professionalisation of political communication. Chicago: University of Chicago Press, 2007, p. 27-46.

NIELSEN, R. K.; VACCARI, C. As pessoas curtem os políticos no Facebook? Não mesmo! A comunicação direta em larga escala entre candidatos e eleitores como um fenômeno outlier. Revista Eletrônica de Ciência Política, v. 5, n. 2, p. 227-256, 2014.

NORRIS, P. Preaching to the converted? Pluralism, participation and party websites. Party Politics, v. 9, n. 1, p. 21-45, 2003.

PANAGOPOULOS, C. Political Consultants, Campaign Professionalization, and Media Attention. PS: Political Science and Politics, v. 39, n. 4, p. 867-869, 2006.

POWER, T.; ZUCCO JR., C. (Org.). O Congresso por ele mesmo: autopercepções da classe política brasileira. Belo Horizonte: Editora UFMG, 2011.

ROSSETTO, Graça; CARREIRO, Rodrigo; ALMADA, Maria Paula. Twitter e comunicação política: limites e possibilidades. Revista Compolítica, v. 2, n. 3, p.189216, jul./dez., 2013.

SANTOS, F. O legislativo em busca de informação: Um estudo da estrutura de assessoria da Câmara dos Deputados. Texto para discussão, v. 1958, p. 1-37, 2014. 
SANTOS, F.; CANELLO, J. Comissões Permanentes, Estrutura de Assessoramento e o Problema Informacional na Câmara dos Deputados do Brasil. Dados, v. 59, n. 4, p. 1127-1168, out. 2016.

TENSCHER, Jens. MPs and the Internet: an empirically based typology. The Journal of Legislative Studies, v. 20, n. 3, p. 305-320, 2014.

THURBER, J. A. The Study of Campaign Consultants: A Subfield in Search of Theory. Political Science and Politics, v. 31, n. 2, p. 145-149, 1998.

VISSERS, Sara. From preaching to the converted to preaching through the converted. In: ECPR Joint Sessions of Workshops. Lisbon: [s.n], 2009.

WARD, S.; LUSOLI, W. 'From Weird to Wired: MPs, the Internet and Representative Politics in the UK', The Journal of Legislative Studies, v. 11, n. 1, 57-81, 2005.

WILLIAMSON, A.;FALLON, F. Transforming the future parliament through the effective use of digital media. Parliamentary Affairs, v. 64, n. 4, 781-792, 2011.

WINZEN, T. Technical or Political? An Exploration of the Work of Officials in the Committees of the European Parliament. The Journal of Legislative Studies, v. 17, n. $1,2011$. 
Tabela 2 - Motivos para estar online, por partido

\begin{tabular}{|c|c|c|c|c|c|c|}
\hline & & $\begin{array}{c}\text { Construção } \\
\text { Imagem }\end{array}$ & $\begin{array}{l}\text { Mobilizar } \\
\text { seguidores }\end{array}$ & $\begin{array}{c}\text { Conquistar } \\
\text { novos } \\
\text { seguidores } \\
\end{array}$ & $\begin{array}{l}\text { Difundir } \\
\text { Conteúdo }\end{array}$ & $\begin{array}{c}\text { Transparênci } \\
\mathbf{a}\end{array}$ \\
\hline Outros & $1^{\circ}$ & $16,70 \%$ & & & $50,00 \%$ & $33,30 \%$ \\
\hline partidos de & $2^{\circ}$ & $16,70 \%$ & $16,70 \%$ & & $16,70 \%$ & $50,00 \%$ \\
\hline \multirow[t]{3}{*}{ Esquerda } & $3^{\circ}$ & $16,70 \%$ & $66,70 \%$ & $16,70 \%$ & & \\
\hline & $4^{\circ}$ & $16,70 \%$ & & $66,70 \%$ & $16,70 \%$ & \\
\hline & $5^{\circ}$ & $33,30 \%$ & $16,70 \%$ & $16,70 \%$ & $16,70 \%$ & $16,70 \%$ \\
\hline \multirow{5}{*}{$\begin{array}{c}\text { PDT-PSB- } \\
\text { PV }\end{array}$} & $1^{\circ}$ & $21,40 \%$ & $28,60 \%$ & & $14,30 \%$ & $14,30 \%$ \\
\hline & $2^{\circ}$ & $14,30 \%$ & $14,30 \%$ & $14,30 \%$ & $14,30 \%$ & $21,40 \%$ \\
\hline & $3^{\circ}$ & $35,70 \%$ & & $14,30 \%$ & $14,30 \%$ & $14,30 \%$ \\
\hline & $4^{\circ}$ & $7,10 \%$ & $7,10 \%$ & $35,70 \%$ & $7,10 \%$ & $21,40 \%$ \\
\hline & $5^{\circ}$ & & $28,60 \%$ & $14,30 \%$ & $28,60 \%$ & $7,10 \%$ \\
\hline \multirow[t]{5}{*}{ PT } & $1^{\circ}$ & $8,30 \%$ & $8,30 \%$ & $12,50 \%$ & $33,30 \%$ & $33,30 \%$ \\
\hline & $2^{\circ}$ & $16,70 \%$ & $16,70 \%$ & $16,70 \%$ & $20,80 \%$ & $25,00 \%$ \\
\hline & $3^{\circ}$ & $25,00 \%$ & $29,20 \%$ & $16,70 \%$ & $8,30 \%$ & $4,20 \%$ \\
\hline & $4^{\circ}$ & $12,50 \%$ & $12,50 \%$ & $33,30 \%$ & $12,50 \%$ & $12,50 \%$ \\
\hline & $5^{\circ}$ & $25,00 \%$ & $20,80 \%$ & $12,50 \%$ & $12,50 \%$ & $12,50 \%$ \\
\hline \multirow[t]{5}{*}{ PMDB } & $1^{\circ}$ & $16,70 \%$ & $20,80 \%$ & $8,30 \%$ & $20,80 \%$ & $29,20 \%$ \\
\hline & $2^{\circ}$ & $12,50 \%$ & $16,70 \%$ & $16,70 \%$ & $29,20 \%$ & $25,00 \%$ \\
\hline & $3^{\circ}$ & $25,00 \%$ & $8,30 \%$ & $29,20 \%$ & $16,70 \%$ & $8,30 \%$ \\
\hline & $4^{\circ}$ & $16,70 \%$ & $29,20 \%$ & $20,80 \%$ & $8,30 \%$ & $12,50 \%$ \\
\hline & $5^{\circ}$ & $20,80 \%$ & $16,70 \%$ & $16,70 \%$ & $16,70 \%$ & $16,70 \%$ \\
\hline \multirow[t]{5}{*}{ PSDB } & $1^{\circ}$ & $8,30 \%$ & & & $41,70 \%$ & $58,30 \%$ \\
\hline & $2^{\circ}$ & $16,70 \%$ & $16,70 \%$ & $25,00 \%$ & $25,00 \%$ & $16,70 \%$ \\
\hline & $3^{\circ}$ & & $8,30 \%$ & $25,00 \%$ & $25,00 \%$ & $16,70 \%$ \\
\hline & $4^{\circ}$ & $16,70 \%$ & $33,30 \%$ & $25,00 \%$ & & \\
\hline & $5^{\circ}$ & $41,70 \%$ & $25,00 \%$ & $8,30 \%$ & & \\
\hline \multirow[t]{5}{*}{ DEM-PSD } & $1^{\circ}$ & $21,10 \%$ & $15,80 \%$ & $5,30 \%$ & $26,30 \%$ & $52,60 \%$ \\
\hline & $2^{\circ}$ & $5,30 \%$ & $10,50 \%$ & & $47,40 \%$ & $31,60 \%$ \\
\hline & $3^{\circ}$ & $15,80 \%$ & $10,50 \%$ & $36,80 \%$ & $10,50 \%$ & $15,80 \%$ \\
\hline & $4^{\circ}$ & $5,30 \%$ & $36,80 \%$ & $36,80 \%$ & $10,50 \%$ & \\
\hline & $5^{\circ}$ & $47,40 \%$ & $21,10 \%$ & $15,80 \%$ & $5,30 \%$ & \\
\hline \multirow{5}{*}{$\begin{array}{c}\text { Outros } \\
\text { partidos de } \\
\text { Direita }\end{array}$} & $1^{\circ}$ & $17,80 \%$ & $2,20 \%$ & $11,10 \%$ & $22,20 \%$ & $42,20 \%$ \\
\hline & $2^{\circ}$ & $17,80 \%$ & $15,60 \%$ & $8,90 \%$ & $24,40 \%$ & $20,00 \%$ \\
\hline & $3^{\circ}$ & $17,80 \%$ & $24,40 \%$ & $17,80 \%$ & $13,30 \%$ & $6,70 \%$ \\
\hline & $4^{\circ}$ & $11,10 \%$ & $22,20 \%$ & $20,00 \%$ & $11,10 \%$ & $15,60 \%$ \\
\hline & $5^{\circ}$ & $17,80 \%$ & $17,80 \%$ & $24,40 \%$ & $17,80 \%$ & $2,20 \%$ \\
\hline
\end{tabular}

Fonte: Elaboração própria.

Artigo submetido em: 2018-09-30

Reapresentado em: 2018-12-13

Aceito em: 2019-01-15 